\title{
Building effective networks: Network strategy and emerging virtual organizations
}

Chapter · January 2010

CITATION

1

2 authors:
READS

26

Some of the authors of this publication are also working on these related projects:

Project

Entrepreneurship Research View project

Project

\section{Ingrid AM Wakkee}

Amsterdam University of Applied Sciences/Cen...

32 PUBLICATIONS 172 CITATIONS

SEE PROFILE
Peter Groenewegen

VU University Amsterdam

127 PUBLICATIONS 1,010 CITATIONS

SEE PROFILE

Real world resilience and organisational resilience in emergency response organisations View project

All content following this page was uploaded by Peter Groenewegen on 14 November 2016. 


\title{
Chapter 4
}

\section{Building Effective Networks:}

\section{Network Strategy and Emerging Virtual Organizations}

\author{
INGRID WAKKEE, PETER GROENEWEGEN, and PAULA DANSKIN ENGLIS
}

Recent studies have broadened the perspective on different types of social, virtual, and organizational networks (Byrne, 1993; Lawrence, Morse, \& Fowler, 2005). Yet, few models have been developed so far that explain the behaviour of emerging transnational organizations and how these can become 'liberated from geographic constraints by quantum leaps in communications, computing, and transportation technologies; unbound from traditional organizational structures by ongoing experimentation in management technology,' and necessitated by mounting pressures of global competition (Parkhe, Wasserman, \& Ralston, 2006: 560). The purpose of this chapter, therefore, is to examine how transnational entrepreneurs (TEs) become immersed in their country of origin, their host country, and even the rest of the world, and what the causal relationships are between networking strategies employed by such ventures and their usage of virtual and social networks.

Building on the literature in the field of organization science, social network theory, and entrepreneurship we develop a matrix consisting of two dimensions: network structure and network strategy. The cells in the matrix give rise to a series of propositions regarding effective 
network building and how this leads to more traditional versus more virtual modes of organization.

In this chapter, we focus on a micro-level perspective in terms of organizational development and relate this development to the entire network rather than the ego-network, thereby discerning between small-world and scale-free network structures (Watts, 1999). Thus when examining what networking strategies lead to virtual modes of organizing, we explore how transnational entrepreneurs position themselves within already existing networks in their home and host country and how they create either new clusters/cliques or how they alternatively seek to establish the large number of ties needed to survive in scale-free network structures.

The chapter is organized as follows. First, we discuss the concept of transnational entrepreneurship (TE) from both a sociological and international management perspective. Second, we discuss the issue of virtualness in organizations including a review of common organizational characteristics for more virtual versus more traditional organizations. Next, we discuss to what extent previous insights into the role of social networks in organizational emergence can be aligned with the notion of virtualness in order to develop a better understanding of the development of transnational ventures. In our view, the level of virtualness of the organization impacts the way network ties support TE processes. We develop a conceptual model that suggests logical ways in which emerging virtual organizations may build effective networks versus more traditional organizations. The chapter closes with a discussion and conclusions.

\section{$<$ H1 $>$ Transnational Entrepreneurship}


Yeung (2002: 30) conceptualizes transnational entrepreneurs as 'businesspersons who take specific proactive action to overcome inherent problems and difficulties associated with international business activities.' He argues that the actions of TEs are strongly influenced by 'the social and business networks, in which these transnational entrepreneurs are embedded, political-economic structures and dominant organizational and cultural practices in the home and host countries' (ibid.).

In sociological studies the concept of transnational entrepreneurship has been used to describe the activities of foreign minorities or ethnic entrepreneurs (EEs) in advanced societies or, alternatively, the activities of Western-educated immigrant engineers who return to their home country mobilizing their cross-country social networks to launch businesses that span international borders (Portes, Guarnizo \& Haller, 2002; Saxenian, 2002). A number of studies have noted the potential significance for TEs to stimulate economic growth in both the receiving country and the country of origin (Zhao, 2005; Saxenian, 2002).

Within the strategic management domain, Bartlett and Ghoshal (1989) discuss transnational strategy in terms of attaining the benefits of global and multidomestic strategies: thinking globally, acting locally. Part of localization is that decision-making and knowledge generation are distributed among the units or entities of a transnational organization, and part of globalization is that this information and knowledge is learned and shared across the firm. The global goal is to integrate components of the business into the overall corporate structure, where each component becomes a source of specialized innovation, while the local goal is to tailor products and services to local needs (Child \& Yan, 2001).

This strategic management perspective of transnationality was originally developed to explain the behaviour of large and established multinational corporations (MNCs); yet, over the 
last two decades two interdependent forces, digitalization and globalization, have led to a world that is characterized by a sort of 'hyperconnectivity' in which even start-ups are confronted from inception with a need to internationalize their own activities or deal with international competition at home (McDougall \& Oviatt, 2005). This leads to a new type of transnational venture that is simultaneously involved in three interrelated aspects of the entrepreneurial process in more than one country : (1) the control of resources in different countries (e.g., capital, information, and knowledge); (2) strategic management in different countries (e.g., innovative and creative deployment of resources); and (3) the creation and exploitation of opportunities in different countries (Yeung, 2002).

In the context of emerging organizations we view transnational entrepreneurship as being represented by a range of cross-border activities. One end is anchored by (temporary) social migration aspects connecting the host country to the home country, as often studied in sociology (Poros, 2001; Kyle, 2000; Basch, Schiller, \& Blanc-Szanton, 1994), while the other end consists of strategic management activities simultaneously capturing global-scale efficiency, responding to national markets, and cultivating a worldwide learning capability for driving continuous innovation across borders (Bartlett \& Ghoshal, 1989). Both ends of this spectrum are important and are substantially different from what is the case with domestic entrepreneurship (Zhao, 2002), and at both ends, the emerging ventures have to manage the dual challenge of globally and locally gaining legitimacy, securing resources, and pursuing opportunities in more than one cultural, social, and economic context. Indeed, McDougall and Oviatt (1996: 36) argue that the internationalization of new ventures 'does not appear to be a simple matter of applying established strategies and procedures developed for a domestic arena. Successful internationalization appears to be accompanied by changes in venture strategy.' 


\section{$<$ H1 $>$ Virtualness}

The term virtual is commonly used to focus attention on those aspects of organization that are not physical or that mainly consist of information and information infrastructures. Two main perspectives on virtual firms can be identified. The first views virtual organizations as temporary alignment networks of alliances between independent ventures or individuals linked (more or less spontaneously) by information technology to share skills, costs, and access to one another's markets using international and communication technology (Byrne, 1993; Chudoba, Wynn, Lu, \& Watson-Manheim, 2005; Jäger \& Steenbakkers, 1997). Such alignments are directed at combining capabilities of partners to specific services or products.

In the second perspective, the label virtual organization is extended into an internal principle of organization within the enterprise (Sandhoff, 1999). The information revolution that has taken place in recent decades has resulted in a situation where almost all, previously physical, elements of an organization can be converted to virtual (Czerniawska \& Potter, 1998). Virtualness, then, is a component of organizing as it takes the form of information-supported interaction to such a degree that it can be considered ubiquitous. Virtual organizations are characterized by digitized social interaction and production processes within the organization and in relation to external network ties. We adopt this latter perspective as we seek to explain how TEs build networks and become immerged in multiple countries.

In the literature attention to virtualness started with an interest in the increasing importance of information and communications technologies. The virtual organization is mentioned as a relevant response to accelerating market changes. Fast changes in consumer 
preferences and demand make it more difficult for traditional companies to respond in timely ways. One solution is to increasingly rely on temporary manufacturing, research, and marketing alliances with others. The resulting networks are geared to exploit a specific opportunity (Byrne, 1993; Hedberg, et al., 1997 ). Hedberg coined the concept of the imaginary organization to get away from "the infotechnical overtones of the term, "virtual"' (Hedberg et al., 1997: p9). Increased virtualness translates to a different type of organization requiring different management practices.

More recent discussions of virtual enterprise organizations reinforce this view (Chudoba et al., 2005). The label virtual enterprise is applicable in the case of tapered and non-integration strategies and can be framed in terms of network organizational structures (Fitzpatrick \& Burke, 2001). In this way, transnational entrepreneurs can gain competitive advantages by providing customers with better and faster service in both the home and host country and possibly even beyond. One example offered by these authors in a manufacturing setting concerns a virtual enterprise that is constructed by partners from different companies, who collaborate with each other to design and manufacture high-quality and customized products. A virtual enterprise is product-oriented, the style is team collaboration, and it features fast and flexible operations. Thus, being an entity constructed from a variety of elements in a loose assemblage that can be disconnected with much effort, a virtual enterprise is distinctively different from a traditional enterprise (Dowlatshahi \& Cao, 2006).

Logically flowing from this view is the claim that virtual organizations are constantly in flux, existing but changing. Saabeel et al. (2002) combined the structural and the process views of virtualness in organizations to characterize virtual organizations in three different layers: a universe of modules, a dynamic web, and a dynamic organization. Each layer has its own 
structural and process characteristics. The notion of change denotes the interaction between the various layers; one layer is coupled to the next. The creation of a common purpose leads to the linking of several independent modules into a dynamic web. If subsequently market opportunities arise, the web may coalesce into a dynamic organization. When value is no longer generated from the opportunity, the organization falls apart into the original modules (Saabeel et al., 2002).

Regarding virtual as process creates the possibility to abandon the binary either/or logic implicitly adopted by many authors and to blur the boundary between traditional and virtual organizations. Indeed, 'firms become more virtual when a larger proportion of important production processes occur outside of traditional organization boundaries' (Kraut et al., 1999: 723-4).

More than two decades ago, Daft and Lengel (1984) argued that new organizing methods, such as virtualization, are likely to affect the extent to which organizational boundaries become increasingly blurred. Thus, traditional firms are likely to have more closed boundaries and virtual firms are likely to have permeable boundaries. Combining the insights from these previous studies Table 4.1 shows the difference between traditional organizing and virtualizing organizations.

<Printer: please insert Table 4.1 about here>

The five dimensions included in Table 4.1 will be used in the remainder of this chapter to determine the degree of virtualness in transnational entrepreneurship. Yet, to fully understand how TEs become embedded in existing networks operating in their home, host, or even global markets we first need to establish the interaction between virtual organizing and social relations. Following Fowler, Lawrence, and Morse (2004), we conclude that there are three main 
differences between socially and virtually embedded ties. First, while socially embedded ties are multiplex and characterized by high levels of reciprocity (Coleman, 1988), virtual ties are likely to be dedicated ties that are easily abandoned after completing a specific task. Second, due to the possibility to rely on electronic forms of communication rather than frequent face-to-face interaction, virtual ties are much less constrained geographically than social ties. Finally, while

most socially embedded ties are based on dyadic relationships, virtual ties are typically based on clusters or coalitions in which multiple ties interact simultaneously with each other.

Consequently, virtualness potentially breaches the gap between arm's-length and embedded social ties (Fowler, Lawrence, \& Morse, 2004; Morse, Fowler, \& Lawrence, 2007).

In the following section, we briefly describe how virtualness affects the emergence of new ventures operating in global markets. Then weexamine what virtual network structures and strategies are associated with TE in increasingly global markets.

\section{$<$ H1 > Transnational Entrepreneurship and Virtualness}

The recognition of opportunities is at the heart of entrepreneurship, and it is the focus on this process that set entrepreneurship studies apart from other management and strategy disciplines (Venkataraman, 1997). The process of recognizing opportunities has been widely studied in recent years (Ardichvili, Cardozo, \& Ray, 2003; Baron, 2006; Krueger \& Dickson, 1994), yet seldom within the context of the virtualization of transnational business. The widespread use of the Internet, however, has not led to the decline of real world opportunity recognition but, on the contrary, it has led to additional possibilities for entrepreneurs to connect information that leads to the discovery of new ideas in several ways (Teece, 1998). First, the borderless nature of the 
Internet has led people to exchange new information with new people around the world that they would not have shared (at all) through other communication channels (Pantelli, 2002). This has allowed TEs to (re-)establish or maintain ties in their country of origin in a much more efficient and effective manner than they could have done even two decades ago. By bridging (previous) structural holes in this manner (Burt, 2004), entrepreneurs are able to connect pieces of information and possibly recognize opportunities to exploit in the real world. Second, wellknown e-commerce examples have shown that not only the process of opportunity recognition can exist in the virtual world, but some opportunities exist only in virtual space leading to the rise of new industries (see, e.g., Shapiro \& Varian, 1999).

To understand how transnational entrepreneurs actually create value from opportunities we need to take two additional processes into consideration: building a resource base and gaining legitimacy (Elfring \& Hulsink, 2003). Building a resource base (Brush et al., 2001; Garnsey, 1998) is essential to develop ideas into opportunities and exploit these successfully across borders. It is highly unlikely that the required resources are available in adequate amounts within the newly formed organization. Moreover, in the early stages of new venture emergence, no revenues are generated to obtain these resources in the marketplace (Brito, 2001).

As argued by Morse, Fowler, and Lawrence (2007), the way transnational entrepreneurs can obtain access to resources, despite their lack of initial (financial) resources to buy others, has changed considerably in the virtual world. First, by becoming virtually embedded TEs can gain access to and acquire external skills, services, and systems that were not previously attainable in either the home or the host country alone. Also, in a virtual environment both the number of potential external network ties and the speed at which the relationships can be established has increased considerably. The establishment of expert and trade communities allows for checking 
the reputation of external parties and the exchange of information with collegial ventures at distant but similar markets. Consequently, it becomes easier to select exchange partners offering good quality goods at the lowest possible prices. Finally, access to funding has become more widespread and easier to locate in the virtual world (e.g., grants and scholarships are advertised online). Alternatively, potential investors can also become aware of the transnational entrepreneur's activities and can make an informed investment decision more easily once the TE has made his or her own presence known online (Morse, Fowler, \& Lawrence, 2007).

Gaining legitimacy involves the process by which transnational entrepreneurs become established and accepted in the home and host market in a sustainable manner, overcoming their 'liability of newness' (Aldrich \& Fiol, 1994; Stinchcombe, 1965). Organizational emergence is typified by significant levels of ambivelance (Gartner, Bird, \& Starr, 1992) and uncertainty in relation to resources, routines, products, and the environment as the emerging venture seeks to do something it has never done before (Hite \& Hesterly, 2001: 277). As argued previously, virtualness is grounded not only in the fact that these TEs are communicating online but also in the way they emerge, organize, and compete (Ehrler, Schőgel, \& Zimmermann, 1999; Teece, 1998). Clearly, this has a significant impact on the way that emerging virtual ventures build legitimacy (Fowler, Lawrence, \& Morse, 2004). Specifically, online communication allows for the widespread dissemination of information regarding the TE's own reliability and helps TEs develop insight into the reliability of their potential trading partners regardless of their location. Further, as argued above, virtual TEs have more possibilities for gaining access to services, networks, and (financial) resources from their country of origin through online communication. By building a resource base more quickly, transnational entrepreneurs are able to reduce their liability of newness, gain market power in both the home and the host country, improve 
efficiency, and enhance learning (Butler \& Croner, 1986), thereby becoming more legitimate partners for others in the industry regardless of their location.

\section{$<$ H1 >Social Networking and Entrepreneurship}

\section{$<$ H2 $>$ Network Structure}

Many authors have indicated that a transnational entrepreneur's strategic advantages or ability to recognize and exploit opportunities flow from his or her position in the network. Entrepreneurs who are more central are more innovative and grow faster (Powell, Koput, \& Smith-Doerr, 1996; Powell et al., 1999). Occupying a structural hole may endow the entrepreneur with information benefits that stimulate new approaches and innovation (Ahuja, 2000). To benefit fully from network positions TEs could benefit from awareness of the structure and the composition of the network. However, in reality, most TEs only have a limited overview of the networks surrounding them in their home and host countries and this is even more the case for the global networks (Shipilov, 2006). At the same time, we do expect that most TEs have a basic understanding of how their network is structured and will at least be able to differentiate between relevant connections, have an insight into the benefits of adding new ties, or 'sense' the advantages of structural holes. This would entail network navigation engaging in different strategies in order to improve their network position. The first of the elements of a strategy is obviously engaging in adding relations that enhance the network position. The second is playing on the cognitive reasons for which potential partners may become interested in engaging with the entrepreneur, for instance, by enhancing the salience of the entrepreneurial efforts (Fund et al., 2008). 
Two recently introduced characterizations of networks - small world and scale free (Watts, 1999) - represent different social processes of the ordering of ties between actors that seem particularly important in the open information and collaboration environment shaped by virtualness. In this chapter we use these two types of network to extend the theories on social cohesion (Coleman, 1988) and brokerage positions between parties (Burt, 1992) to accommodate the influence of networks as more than the effects of bounded and sometimes local social structures. In a way the large-scale networks from which these characterizations are derived extend the relevant network environment for analysis of TE; although the theoretical explanation is still lacking, there is increasing evidence of the similarity in network topography of large (international) systems and TEs.

Small-world networks are characterized by dense cliques of actors connected by relationships that cut across cliques, acting as conduits for information and control (White, 1970). Small-world networks are known for their high degree of clustering and short path length. Clustering refers to the likelihood of two members of a network having a high chance of being acquainted if they have one or more acquaintances in common. Path length refers to the existence of short paths through network structures that link pairs (Watts \& Strogatz, 1998). A large body of research supports the widespread presence of the small-world network structure (Adamic \& Huberman, 2001; Davis, Yoo, \& Baker, 2003; Newman, 2000; Powell et al., 2005; Uzzi \& Spiro, 2005; Watts, 1999; Watts \& Strogatz, 1998). Increased virtual connectedness through the actions by TEs induces possibilities to maintain more random ties, and because of the representation of activities and ideas of diverse groups, fosters the identification of potential gaps that can be breached between dense clusters. Thus, by knitting together various clusters with relatively little effort, a diverse set of capable global communities can be tapped into. 
Scale-free network structures have a highly skewed degree of distribution of their network ties over the nodes in the network. Thus, a small number of members are connected with high numbers of others through a disproportionately large number of ties (Barabasi \& Albert, 1999). With only a few steps, adding ties to well-connected others brings transnational entrepreneurs into contact with a huge number of other potential partners.

Both types of networks exhibit properties that are relevant to entrepreneurial action. The closely linked, dense network clusters characteristic of the small world may represent specialist communities with regard to knowledge; similar clusters may also be representative for niche markets. The clustering represents social groups that offer the possibility to become bridged, allowing for the exploitation of opportunities arising from demand or differentiation in expert knowledge. As Burt (2005) argues, while structural holes may offer rewards, they also may be logical places not to be bridged.

Scale-free networks are representative of a different type of social connections. When the network linkages represent demand for whatever the node can deliver, a node with a high number of linkages can be said to have a higher status (Podolny, 2005). For entrepreneurial action it might imply that maintaining high-status positions requires less time and effort. In addition, such nodes may introduce possibilities for quick interconnections. When seeking out others with high connectedness, the visibility in virtual space can be considered to be much higher.

Introducing the terminology from characterizations of large-scale networks allows for two steps in our model: it identifies dispersed but locally cohesive clusters that seem to be characteristic for the ordering of social and economic activities in the global economy, and it introduces the sort of hyperconnectivity that is part of large-scale networks in the networked 
world. While the first is related to the emergence and interconnections of specialist communities, the latter is a logical representation not only of a changed world but also of the increased communicative networking capabilities in virtual entrepreneurship.

\section{$<$ H2>Network Strategy}

Except for some research on alliance strategies and the underlying processes of partner choice (Gulati \& Gargiulo, 1999; Gulati \& Singh, 1998), there is a surprising lack of network strategy analysis - how a firm chooses network partners. One exception is called the Scandinavian school of network strategy analysis (Gadde \& Håkånsson, 2001; Håkansson, 1989). Only recently has broader attention to network strategy been emerging (Baum \& Rowley, 2008). Within this stream of literature, network cognition is seen as individual and dependent on the ability to convert available information on parties dependent on attention to the position of those other parties (van Liere, Koppius, \& Vervest, 2008). The transnational entrepreneur is bound to use substantial knowledge of the network environment to inform alliance formation and network strategy. Do entrepreneurs manage their networks or do the networks manage the entrepreneurs? Who has control? Managing a network involves a complex sequence of moves and countermoves, adjustments and readjustments, actions and reactions, and even non-actions (McGuire, 2002). As argued by Baum, Shipilov, \& Rowley (2003), small-world networks may arise from chance connections among firms in different cliques. In both scale-free and smallworld networks we can often observe insurgent partnering by peripheral firms to improve their network position and controlled partnering by core firms to maintain their position. 
These arguments suggest that we can distinguish between two types of network strategies: purposeful strategies that are characterized by a high level of strategic intent (Osland \& Yaprak, 1995) or serendipitive strategies where TEs decide to 'go with the flow' and see where the network takes them (Andel, 1994). Purposeful strategies allow TEs to remain in control when seeking new strategies to compete effectively and survive, particularly in rapidly evolving industries and markets (Osland \& Yaprak, 1995: 52) and to maintain their autonomy in other areas (Kosa \& Lewin, 2000). Proactive engagement can also help TEs reduce the uncertainty that is inherent in doing business within and across borders (Osland \& Yaprak, 1995). Indeed, networks offer a 'powerful means for adaptation in turbulent or uncertain environments' (Kosa \& Lewin, 2000: 147), which may be essential for emerging transnational organizations.

Emerging transnational ventures pursuing purposeful network strategies can take a few approaches. When operating in a small-world network structure, they could try to establish connections with a large number of ties in different cliques across countries and thereby improve their own position in the network moving away from the periphery (Madhavan et al., 2008). Alternatively, when embedded in a scale-free network they could attempt to establish a connection to those network actors who have a disproportionate number of ties, as this would not only help them to gain access to resources but also to establish legitimacy relatively quickly and at low cost (Elfring \& Hulsink, 2003).

At first glance, it seems that emerging transnational organizations that do not use proactive engagement to manage their networks but rather opt for the serendipitive approach are likely to be managed by the network. Yet, as pointed out by Baum, Shipilov, and Rowley (2003), chance connections are important in the formation of small-world networks. This suggests that a 
serendipitive strategy involving random rewiring from the perspective of the individual entrepreneur can make sense. Too much planning (or intent) may cause the TE to be less alert to the external environment or block out potentially relevant information that could possibly lead to the recognition of new opportunities (Gaglio \& Katz, 2001; Kirzner, 1973, 1979, 1997). Further, planned behaviour is not always possible (Saxenian, 1994). Organizations may need to give up some autonomy and call on uncommon managerial skills (i.e., managing between organizations rather than within them). This is particularly difficult for emerging organizations and the TEs who lead them since they have few slack resources, and the TEs may have limited experience outside their own organization and little or undeveloped network management skills. This may be compounded when the TE is engaged in an industry area that is not clearly defined or is changing at an unstable pace. In these situations, a large number of random connections may be required (Stacey, 1995). In terms of network structure this would fit the so called scale-free phenomenon (Baum, Shipilov, \& Rowley, 2003). By building random connections TEs can create linkages to communities and groups that have different backgrounds and perspectives, creating opportunities for new ventures.

\section{$<$ H1 $>$ The Model}

Attempts to capitalize on new markets created by open access to organizing information on the Internet have altered the nature of entrepreneurial processes. However, the fundamental changes in the conditions under which TE processes take place due to virtual modes of organizing and networking and their effects on these TE processes have hitherto scarcely been assessed in entrepreneurial theory. We expect that transnational ventures that are more virtually organized 
will be positioned differently in their network and use different network strategies during their emergence than more traditional transnational ventures do. Virtualness eases the scanning for information regarding market opportunities and regarding potentially fruitful business models and partners to exploit these opportunities. When connectivity is used for monitoring, adjustment, and planning, it allows emerging TEs to operate without actually gaining ownership over the resources they need to exploit the recognized opportunity. Lastly, increased accessibility to information on other companies, their operations, and needs allows TEs to draw on a wide variety of examples and schemas and enables them to adjust their legitimization strategies accordingly (Ruef, 2002).

We expect that network structures and strategies change during each of the three processes. Although authors often present these processes of opportunity recognition, gaining legitimacy, and resource building as if they were constructed in a way that appears to be linear and sequential, in fact, the process is dynamic and iterative (Bygrave, Sexton, \& Kasarda, 1992; Ropo \& Hunt, 1995). As shown in Figure 4.1 as the processes unfold, changing circumstances may require actions to change or go back on certain decisions.

$<$ Printer: please insert Figure 4.1 about here>

In the following section we develop a model in which we connect these two domains by suggesting plausible strategies for each of the three entrepreneurial processes (Van Der Veen \& Wakkee, 2006).

The starting point for our model is a matrix consisting of structure and strategy as depicted in Figure 4.2. We argue that emerging organizations may utilize each of the four resulting quadrants in order to become immersed in their market of choice. In the following paragraphs we argue how virtual and traditional TEs move through the different quadrants 
during their processes of opportunity recognition, gaining legitimacy, and building a resource base dependent on their level of virtualness.

<Printer: please insert Figure 4.2 about here>

\section{$<$ H2>Opportunity Recognition}

A classic insight from social network theory, that is, brokerage and closure (Burt, 2005 , is when a known multitude of loosely unconnected or sparsely connected regions exists using strategic intent to occupy and maintain structural holes as active bridged groups. Brokerage allows emerging ventures to benefit from clearly articulated needs or insights in coherent communities or market niches. Increased networking capability will lead to the ability to organize linkages to a larger variety of groups. A large number of random connections in a network is more likely to increase creativity and, perhaps, opportunity recognition. While recognition of differences is essential, it is not clear from the outset that advantages may be obtained. Although brokerage is an articulate act, it would be extraordinary for the connection of clusters providing new ideas that only the TE would benefit with a clear vision of the overall structure. Thus, by undertaking more random or serendipitive connections in a network, a TE is more likely to develop a highly flexible response to external environmental opportunities. Therefore, the strategy of nonproactive network engagement or even 'muddling through' (Lindblom, 1959) may be more appropriate for acquiring new ideas in highly competitive, emerging technological arenas (Quinn, 1980).

We argue that transnational organizations that are more virtually organized will be better able to follow these desired patterns of interaction than traditional transnational firms. The low marginal costs of adding additional contacts and the ability to connect to individuals and 
organizations around the globe facilitates occupying positions of brokerage as well as random rewiring, allowing entrepreneurs to bridge structural holes and connect pieces of information that lead to the recognition of opportunities (Burt, 1992). Further, in the virtual world, the exchange of information does not only take place on a dyadic level between individuals and organizations but rather in so-called communities of problem solving that can be characterized as small-world networks. The existence of communities of problem solving implies that online structural holes do not exist between individuals but rather between communities. This means that if TEs are searching for opportunities they should become aware of the capabilities of multiple communities. If they engage in interaction with these communities, they either can forge linkages from within the community or between communities. While Burt's (2004) structuralhole argument is based on both information differentiation and networking efficiency, in terms of the energy spent on contacts, the shift to virtual ties enables a broader range of strategies. More time implies a potentially closer alliance with relevant communities across borders, even perhaps embeddedness in more than one community, as well as the ability to occupy more gaps between clusters in different countries. The main benefit of doing so is that entrepreneurs are not only able to obtain access to information from various sources, but to use information that has been validated within and by the communities where it originates (Fowler, Lawrence, \& Morse, 2004). These different forms of network engagement or strategy are more likely to produce a changing variety of emergent patterns of interaction to match external change. The underlying combination of virtualness and small network characteristics leads to a higher number of small network linkages. 
Proposition 1: During opportunity recognition, transnational entrepreneurs with emerging virtual organizations are more likely to encounter more unintentional contact with a variety of clusters to recognize opportunities than transnational entrepreneurs with emerging traditional organizations (thus they will operate in Quadrant 1).

\section{$<$ H2>Building a Resource Base}

To develop ideas into opportunities and exploit these successfully, emerging ventures must build a resource base (Brush et al., 2001). Limited size and age make it unlikely that the resource base is available within the boundary of the firm or that it can be obtained by economic transactions in the marketplace. Social networking has often been seen as the main way to compensate for this lack (e.g., Birley, 1985; Elfring \& Hulsink, 2003). It has been argued that particularly strong ties (Elfring \& Hulsink, 2003; Granovetter, 1973) should be used for this purpose as they might be willing to provide resources below market price. In a traditional world only a limited number of strong ties can be maintained (Granovetter, 1973; White \& Houseman, 2003). This suggests that purposeful establishment of linkages to so-called super nodes or hubs in scale-free networks are a fruitful strategy for building a resource base. By being connected to a much larger than average share of contacts in the network, these super nodes provide the network with searchability from a global perspective (Barabasi \& Albert, 1999). As such connections are available to competitors these network contacts will mainly function to routinize connections to resources such as capital that are accessed on a regular basis. 
Proposition 2a: Transnational entrepreneurs with emerging traditional organizations are more likely to engage in purposefully establishing connection to super nodes in scale-free networks to develop a resource base than transnational entrepreneurs with emerging virtual organizations (thus they will operate in Quadrant 4).

It has been suggested that the more virtual a venture is, the more likely it uses resources that are external to the company while more traditional ventures seek to gain access to resources by obtaining ownership of these or by creating them internally (Kraut et al., 1999). This approach leads to a focus on establishing partnerships for exploiting their opportunity (Dowlatshahi \& Cao, 2006; Fitzpatrick \& Burke, 2001). As argued previously, these (information-based) capabilities are developed not through dyadic interactions, but in different clusters and coalitions.

In a virtual world, the limited marginal costs associated with adding (virtual) connections enable TEs operating in small-world networks to easily and rapidly access a vast range of individuals, organizations, and communities with specialized information, skills, and experience. In such networks, the actors are not as much motivated by reciprocal services and the need to build long-term socially embedded relationships as by expected return in reputation effects stemming from the visible exchange of information and other resources within the coalition (Fowler, Lawrence, \& Morse, 2004; Morse, Fowler, \& Lawrence 2007). To benefit from this, TEs operating in small-world networks will engage in purposefully establishing connections to various functionally differentiated clusters. Their ability to organize their resources in this way may be based on elements that are traditionally regarded as internal to such production capacity or external with suppliers or in cooperation with customers. Constraints on working together in 
this fashion are eased by the ability to apply a variety of tools provided by interconnectedness and digital content of primary processes. Therefore, with regard to emerging small-world networks, we expect strategies to be stable in Quadrant 2. Thus, the following proposition is offered:

Proposition 2b: Transnational entrepreneurs with emerging virtual organizations are more likely to purposefully establish contacts with a variety of clusters in small-world networks to build their resource base than transnational entrepreneurs with emerging traditional organizations (thus they will operate in Quadrant 2).

\section{$<$ H2>Gaining Legitimacy}

To establish a market position and overcome their 'liability of newness' (Aldrich \& Fiol, 1994; Stinchcombe, 1965), all emerging ventures need to gain legitimacy. It is well known in classic network theory that ventures that are connected to a common partner can obtain reliable information about each other from that partner (Baker, 1990; Burt \& Knez, 1995; Elfring \& Hulsink, 2003).

As argued by Stuart, Hoang, and Hybels (1999), particularly new ventures that are based on radical innovations or business models need endorsements from some of the prominent players in the industry, as their information is often considered more valuable than that of less prominent players. Because prominent players are also expected to have a higher than average connectivity, being associated with such 'super nodes' also increases the visibility of the new 
venture (Barabasi \& Albert, 1999). Thus, it seems that establishing connections to super nodes in scale-free networks would seem to be a favourable strategy in this situation. Such strategies are also common in building relations by high-tech ventures, for instance, associating with large companies to establish credibility. We argue that TEs who operate in a virtual mode can more easily identify organizations with characteristics relevant for them. Thus, we propose:

Proposition 3a: Transnational entrepreneurs with emerging traditional organizations are more likely to engage in purposefully establishing connection to super nodes in scale-free networks to build legitimacy than transnational entrepreneurs with emerging virtual organizations (thus they will operate in Quadrant 4).

In the context of virtual networks, however, the high level of connectedness of smallworld networks will lead information to spread and be validated rapidly within the cluster (Fowler, Lawrence, \& Morse, 2004; Morse, Fowler, \& Lawrence 2007). Emerging TEs can thus build reputation by contributing small pieces of information to the discussions in the cluster even without being connected directly to a prominent partner with above average connectivity. In small-world networks, new ventures thus benefit from the fleeting character and randomness of virtual contacts across geographically dispersed clusters to spread reputation, thus fostering the development of legitimacy beyond their local network. Thus the final proposition offered is: 
Proposition 3b: During legitimization, transnational entrepreneurs with emerging virtual organizations will be more likely to use unintentional contacts with small-world networks to build legitimacy than transnational entrepreneurs with emerging traditional organizations.

\section{$<$ H1 $>$ Discussion and Conclusion}

The purpose of this chapter has been to examine how emerging organizations become immersed in the markets in which they operate and what the causal relationships are between network strategies that are enabled by a switch from social to more virtual networks. We argued that it is important to consider how emerging ventures position themselves within an existing network, how they are enabled by new tools to create linkages with a variety of clusters/cliques, and how they are able to establish a large number of ties, leading to a discussion of options open in a small-world or scale-free network. In particular we focused on the differences between virtual and traditional emerging organizations in relation to their network strategies and structures during the processes of opportunity recognition, resource-building, and gaining legitimacy and formulated propositions associated with these differences. Clearly, future research is required to elaborate these propositions and test them in an empirical setting. Yet, with this conceptual chapter, we contribute to several theoretical debates within entrepreneurship and networking.

The main contribution is a theoretical framework that starts to specify two developments that characterize organizing in the Internet age. First, we are drawing attention to the potential application of recent discussions on social network theory. The propositions address the challenges to develop theory that makes use of these new tools (Uzzi \& Spiro, 2005). Both 
small-world and scale-free networks suggest strategy formation in a way that may be based on enabling and limiting embedded action because of the added abilities of virtualization. Also our approach promises continuity with core elements of the research body on brokerage and closure on the role of structure. The main new opening concerns the extension of virtualization.

Our work also contributes to the theory of transnational entrepreneurship. Despite the fact that many scholars have pointed to the importance of the Internet in explaining the emergence of international and transnational new ventures, until now a theoretical conceptualization regarding virtualization of both networks and business models was absent from the debate within the TE field. Following Kleinberg (2000), we showed that network structure is important not only locally (i.e., because an entrepreneur's neighbourhood provides access to the information and resources to recognize and exploit opportunities) but also globally, as it enables the entrepreneur to navigate when searching for information and resources outside his or her neighbourhood (Watts, 2004). This might explain how transnational new ventures have been able to become involved in activities around the world from a very early stage in their existence.

\section{Acknowledgment}

The authors thank the anonymous reviewers of the Academy of Management Conference 2007, as well as the organizers and participants of the NeXt (Centre Nascent Entrepreneurship and the Exploitation of Technology) Conference at Wilfrid Laurier in Waterloo, Ontario, Canada. April $28^{\text {th }} 2008$

\section{$<$ H1 $>$ References}


Adamic, L.A., \&Huberman, B.A. (2001). The Web's hidden order. Communications of the ACM 44(9): 55-60.

Ahuja. (2000). The duality of collaboration: Inducements and opportunities in the formation of interfirm linkages. Strategic Management Journal, 21: 317-343.

Aldrich, H.E., \& Fiol, C.M. (1994). Fools rush in? The institutional context of industry creation. Academy of Management Review 19(4): 645-670.

Andel, P. (1994). Anatomy of the unsought finding serendipity: Origin, history, domains, traditions, appearances, patterns and programmability. British Journal for the Philosophy of Science 45(2): 631-648.

Ardichvili, A., Cardozo, R., \& Ray, S. (2003). A theory of entrepreneurial opportunity identification and development. Journal of Business Venturing 18(1): 105-123.

Baker, W.E. (1990). Market networks and corporate behavior. American Journal of Sociology 96: 589-625.

Barabasi, A.L., \& Albert, R. (1999). Emergence of scaling in random networks. Science 286: 509-51.

Baron, R.A. (2006). Opportunity recognition as pattern recognition: How entrepreneurs 'connect the dots' to identify new business opportunities. Academy of Management Perspectives 20(1): 104-119.

Bartlett, C.A., \& Ghoshal, S. (1989). Managing across Borders: The Transnational Solution. Boston: Harvard Business School Press.

Basch, L., Glick Schiller, N., \& Szanton Blanc, C. (1994). Nations Unbound: Transnational Projects, Postcolonial Predicaments, and Deterritorialized Nationstates. Amsterdam: Gordon and Breach 
Baum, J. A. C. and Rowley, T. J. (2008), "Evolving webs in network economies”, Baum, J. A.C. and T. J. Rowley (eds.) pp xiii-xxxii, Advances in Strategic Management Volume 25 Oxford UK: Emerald

Baum, J.A.C., Shipilov, A.V., \& Rowley, T.J. (2003). Where do small worlds come from? Industrial and Corporate Change 12(4): 697-725.

Birley, S. (1985). The role of networks in the entrepreneurial process. Journal of Business Venturing 1: 107-117.

Brito, C.M. (2001). Towards an institutional theory of the dynamics of industrial networks. Journal of Business and Industrial Marketing 16(3): 150-166.

Brush, C.G., Greene, P.G., Hart, M.M., \& Haller, H.S. (2001). From initial idea to unique advantage: The entrepreneurial challenge of constructing a resource base. Academy of Management Executive 15(1): 64-78.

Burt, R.S. (1992). Structural Holes: The Social Structure of Competition. Cambridge: Harvard University Press.

Burt, R.S. (2004). Structural holes and good ideas. American Journal of Sociology 110: 349-399.

Burt, R.S. (2005). Brokerage and Closure. An Introduction to Social Capital. Oxford: Oxford University Press.

Burt, R.S., \& Knez. M. (1995). Kinds of third-party effects on trust. Rationality and Society 7 : $225-292$.

Butler, R., \& Croner, M. (1986). Strategy and strategic choice: The case of telecommunications. Strategic Management Journal 7: 161-177.

Bygrave, W., Sexton,D., \& Kasarda, J. (1992). The state of the art of entrepreneurship. Boston. MA: PWS-Kent. 
Byrne, J.A. (1993). The Virtual Corporation. Business Week 8: 98-103.

Child, J., \& Yan, Y. (2001). National and transnational effects in international business. Management International Review 41(1): 53-75.

Chudoba, K.M., Wynn, E., Lu,M., \& Watson-Manheim, M.B. (2005). How virtual are we? Measuring virtuality and understanding its impact in a global organization. Information Systems Journal 15(4): 279-306.

Coleman, J.S. (1988). Social capital in the creation of human-capital. American Journal of Sociology 94: 95-120.

Czerniawska, F., \& Potter, G. (1998). Business in a Virtual World. Exploiting Information for Competitive Advantage. Houndmills: Macmillan.

Daft, R.L., \& Lengel, R.H. (1984). Information richness: A new approach to managerial information processing and organizational design. Research in Organizational Behavior 6: 191-234.

Davis, G.F., Yoo, M., \& Baker, W.E. (2003). The small world of the American corporate elite, 1982-2001. Strategic Organization 1(3): 301-326.

Dowlatshahi, S., \& Cao, O. (2006). The relationships among virtual enterprise, information technology, and business performance in agile manufacturing: An industry perspective. European Journal of Operational Research 174(2): 835-860.

Ehrler, B., Schőgel, M., \& Zimmermann. H.D.(1999). The virtualization of value creation. Journal of Organizational Virtualness 1(1): 262-264.

Elfring, T., \& Hulsink, W. (2003). Networks in entrepreneurship: The case of high-technology firms. Small Business Economics 21(4): 409-422. 
Fitzpatrick, W.M., \& Burke, D.R. (2001). Virtual venturing and entry barriers: Redefining the strategic landscape. SAM Advanced Management Journal 66(4): 22-30.

Fowler, S.W., T.B. Lawrence, and E.A. Morse. (2004). 'Virtually Embedded Ties.' Journal of Management 30(5): 647-66.

Fund, B. R., Pollock, T. G., Baker, T., \& Wowak, A. J. 2008. Who's the New Kid? The Process of Developing Centrality in Venture Capitalist Deal Networks. Network Strategy, 25: 563593.

Gadde, L.E., \& Håkånsson, H. (2001). Supply Network Strategies. Chichester: Wiley.

Gaglio, C.M., \& Katz, J. (2001). The psychological basis of opportunity identification: Entrepreneurial alertness. Small Business Economics 16: 95-111.

Garnsey, E. (1998). A theory of the early growth of the firm. Industrial and Corporate Change 7(3): 523-556.

Gartner, W.B., Bird, B.J.,\& Starr, J.A. (1992). Acting as if: Differentiating entrepreneurial from organizational behavior. Entrepreneurship Theory and Practice 16(3): 13-31.

Granovetter, M. (1973). The strength of weak ties. American Journal of Sociology 78(6): 13601380.

Gulati, R., \& Gargiulo, M. (1999). Where do interorganizational networks come from? American Journal of Sociology 104(5): 1439-1493.

Gulati, R., \& Singh, H. (1998). The architecture of cooperation: Managing coordination costs and appropriation concerns in strategic alliances. Administrative Science Quarterly 43: 781814.

Håkansson, H. (1989). Corporate Technological Behaviour, Co-operation and Networks. London: Routledge. 
Hedberg, B., Dahlgren, G., Hansson, J., \& Olve, N.G. (1997 ). Virtual Organizations and Beyond: Discover Imaginary Systems. Baffins Lane: Wiley.

Hite, J.M., \& Hesterly, W.S. (2001). The evolution of firm networks: From emergence to early growth of the firm. Strategic Management Journal 22: 275-286.

Jäger, H.W.J., \& Steenbakkers, S. (1997). Characteristics of virtual organizations. Electronic Journal of Organizational Virtualness 1: 65-76.

Kirzner, I. (1973). Competition and Entrepreneurship. Chicago: University of Chicago Press.

Kirzner, I. (1979). Perception, Opportunity and Profit: Studies in the Theories of Entrepreneurship. Chicago: University of Chicago Press.

Kirzner, I. (1997). Entrepreneurial discovery and the competitive market process: An Austrian approach. Journal of Economic Literature 35: 60-85.

Kleinberg, J. (2000). Navigation in a small world. Nature 406(6798): 845.

Kosa, M., \& Lewin, A. (2000). Managing partnerships and strategic alliances: Raising the odds of success. European Journal of Management 18(2): 146-151.

Kraut, R.C., Steinfield, A.P., Butler, B., Chan, A.P.,\& Hoag, A. (1999). Coordination and virtualization: The role of electronic networks and personal relationships. Organization Science 10(6): 722-740.

Krueger, N., \& Dickson, P.R. (1994). How believing in ourselves increases risk taking: Perceived self-efficacy and opportunity recognition. Decision Sciences 25(3): 385-400.

Kyle, D. (2000). Transnational Peasants: Migrations, Networks, and Ethnicity in Andean Ecuador. Baltimore: Johns Hopkins University Press.

Lawrence, T.B., Morse, E.A., \& Fowler, S.W. (2005). Managing your portfolio of connections. Mit Sloan Management Review 46(2): 59-62. 
Lindblom, C.E. (1959). The science of 'muddling through.' Public Administration Review 19: 79-88.

Madhavan, R. Caner, T., Prescott, J., Koka, B. (2008), "Networking as antecedent to network structure", JAI/Emerald Group, Bingley, UK, pp.457 - 501

McDougall, P.P., \& Oviatt, B.M. (1996). New venture internationalization, strategy, change, and performance: A follow-up study.' Journal of Business Venturing 11(1): 23-40.

McGuire, M. (2002). Managing networks: Propositions on what managers do and why they do it. Public Administration Review 62(5): 599-609.

Morse, E., Fowler, S., \& Lawrence,T. (2007). The impact of virtual embeddedness on new venture survival: Overcoming the liabilities of newness. Entrepreneurship Theory and Practice 31(2): 139-159.

Newman, M.E.J. (2000). Models of the small world. Journal of Statistical Physics 101(3): 819841.

Osland, G.E., \&Yaprak, A. (1995). Learning through strategic alliances. European Journal of Marketing 29(3): 52-66.

Oviatt, B.M., \& McDougall, P.P. (2005). Defining international entrepreneurship and modeling the speed of internationalization. Entrepreneurship Theory and Practice 29: 537-554.

Pantelli, N. (2002). Richness, power cues, and Email text. Information \& Management 40: 7578.

Parkhe, A., Wasserman, S., \& Ralston, D. (2006). New frontiers in network theory development. Academy of Management Review 31: 560-568.

Podolny, J.M. (2005). Status Signals: A Sociological Study of Market Competition. Princeton: Princeton University Press. 
Poros, M.V. (2001). The role of migrant networks in linking local labour markets: The case of Asian Indian migration to New York and London. Global Networks: A Journal of Transnational Affairs 1: 243-260.

Portes, A., Guamizo, L.M. \& Haller,W.J. (2002). Transnational entrepreneurs: An alternative form of immigrant economic adaptation. American Sociological Review 67:278-298.

Powell, W.W., Koput, K.W., \& Smith-Doerr, L. (1996). Interorganizational collaboration and the locus of innovation: Networks of learning in biotechnology. Administrative Science Quarterly 41: 116-145.

Powell, W.W., Koput, K.W., Smith-Doerr, L., \& Owen-Smith, J. (1999). Network Position and Firm Performance: Organizational Returns to Collaboration in the Biotechnology Industry. Stanford: JAI Press.

Powell, W.W., White, D.R., Koput, K.W., \& Owen-Smith, J. (2005). Network dynamics and field evolution: The growth of interorganizational collaboration in the life sciences. American Journal of Sociology 110(4): 1132-1205.

Quinn, J.B. (1980). Strategies for Change: Logical Incrementalism. Homewood: Richard D. Irwin.

Ropo, A., \& Hunt, J.G. (1995). Entrepreneurial processes as virtuous and vicious spirals in a changing opportunity structure: A paradoxical perspective. Entrepreneurship: Theory and Practice 19(3): 91-111.

Ruef, M. (2002). Strong ties, weak ties and islands: Structural and cultural predictors of organizational innovation. Industrial and Corporate Change 11(3): 427-449. 
Saabeel, W., Verduijn, T.M., Hagdorn, L., \& Kumar, K. (2002). A model of virtual organisation: A structure and process perspective. Electronic Journal of Organizational Virtualness 4(4): $1-16$.

Sandhoff, G. (1999). Virtual organizations as power-asymmetrical networks. Electronic Journal of Organizational Virtualness 1(1): 103-119.

Saxenian, A. (1994). Regional Advantage: Culture and Competition in Silicon Valley and Route 128. Cambridge: Harvard University Press.

Saxenian, A.L. (2002). Silicon Valley's new immigrant high-growth entrepreneurs. Economic Development Quarterly 16: 20.

Schultze, U. \& Orlikowski, W.J. (2001) Metaphors of virtuality: shaping an emergent reality. Information \& Organization 11, 45-77.

Shapiro, C., \& Varian, H.R. (1999). Information Rules: A Strategic Guide to the Network Economy. Cambridge: Harvard Business School Press.

Shipilov, A.V. (2006). Network strategies and performance of Canadian investment banks. Academy of Management Journal 49(3): 590-604.

Stacey, R.D. (1995). The science of complexity: An alternative perspective for strategic change processes. Strategic Organization 16: 477-495.

Stinchcombe, A.L. (1965). Social structure and organizations. In J.G. March (Ed.), Handbook of Organizations, 142-193. Chicago: Rand McNally.

Stuart, T.E., Hoang, H., \& Hybels, C. (1999). Interorganizational endorsements and the performances of entrepreneurial ventures. Administrative Science Quarterly 44: 215-349.

Teece, D. (1998). Capturing value from knowledge assets: The new economy, markets for knowhow, and intangible assets. California Management Review 40(3): 55-79. 
Uzzi, B., \& Spiro, J. (2005). Collaboration and creativity: The small world problem. American Journal of Sociology 111(2): 447-504.

Van Der Veen, M., \& Wakkee, I. (2006). Understanding the entrepreneurial process.' In P. Davidsson (Ed.), New Firm Startups. <AU: page numbers?> Cheltenham: Edward Elgar. van Liere, D.W., Koppius O.R, \& Vervest P. H.M. 2008. Network Horizon: An InformationBased View on the Dynamics of Bridging Positions. In Joel A.C. Baum and Tim J. Rowley (eds.) Network Strategy Advances in Strategic Management Volume 25: 595-639. Oxford UK: Emerald

Venkataraman, S. (1997). The distinctive domain of entrepreneurship research: An editor's perspective. In Advances in Entrepreneurship, Firm Emergence and Growth, 119-138. Greenwich: JAI Press.

Watts, D.J. (1999). Small Worlds: The Dynamics of Networks between Order and Randomness. Princeton: Princeton University Press.

Watts, D.J. (2004). The 'new' science of networks. Annual Review of Sociology 30: 243-270.

Watts, D.J., \& Strogatz, S.H. (1998). Collective dynamics of 'small-world' networks. Nature 393(6684): 409-410.

White, D.R., \& Houseman, M. (2003). The navigability of strong ties: Small worlds, tie strength, and network topology self-organization in strong-tie small worlds. Complexity 8(1): 72-81.

White, H.C. (1970). Search parameters for the small world problem. Social Forces 49: 259-264

Yeung, H. (2002). Entrepreneurship in international business: An institutional perspective. Asia Pacific Journal of Management 19(1): 29-61.

Zhao, F. (2005) 'Exploring the Synergy between Entrepreneurship and Innovation', International Journal of Entrepreneurial Behaviour and Research 11(1): 25-42. 
Table 4.1 Difference between Traditional and Virtual Organizations

\begin{tabular}{|l|l|l|}
\hline Dimension & Traditional & Virtual \\
\hline (Physical) Structure & Building & Platform \\
\hline Boundary & Fixed entity & Permeable \\
\hline Location & Place & Space \\
\hline Governance & Command and control & Community and coalition \\
\hline Existence & Finalization & Flux \\
\hline
\end{tabular}

Source: Derived from Schultze and Orlikowski (2001). 
Figure 4.1. A model of organizational emergence. Source: Van der Veen and Wakkee (2006).

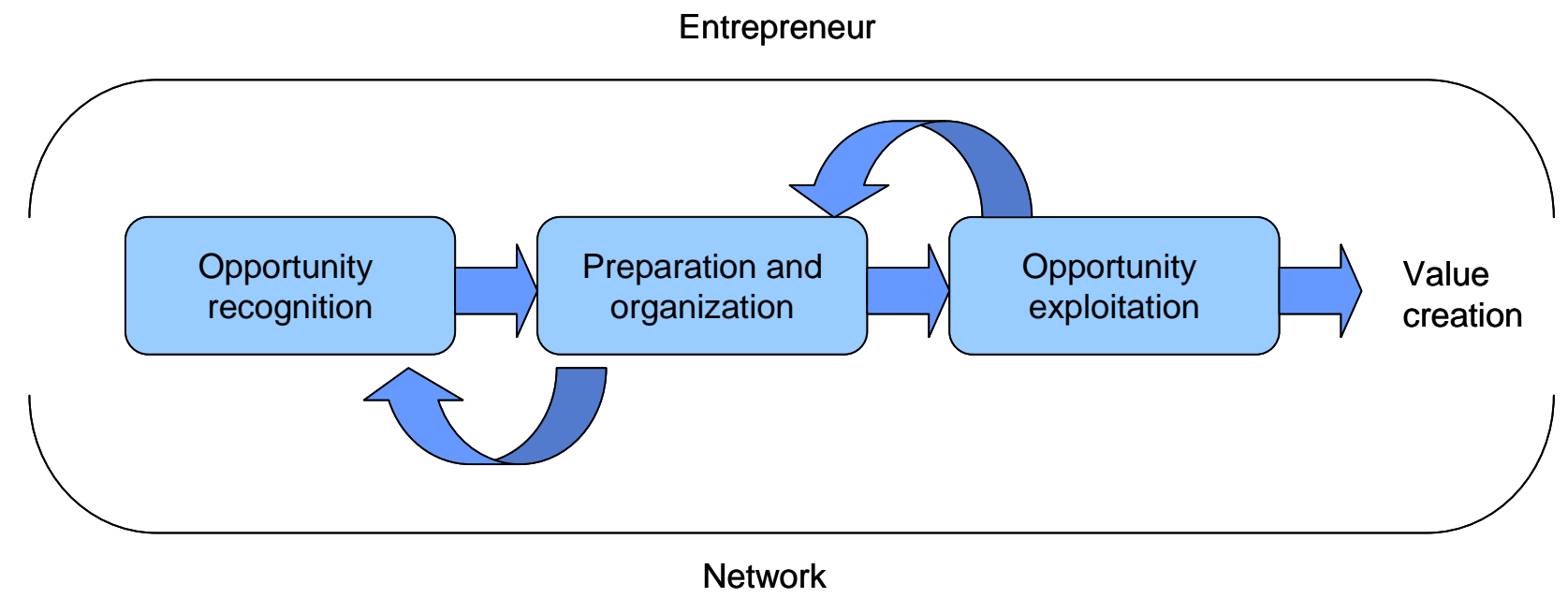


Figure 4.2. The impact of network strategy and structure on emerging virtual organizations.

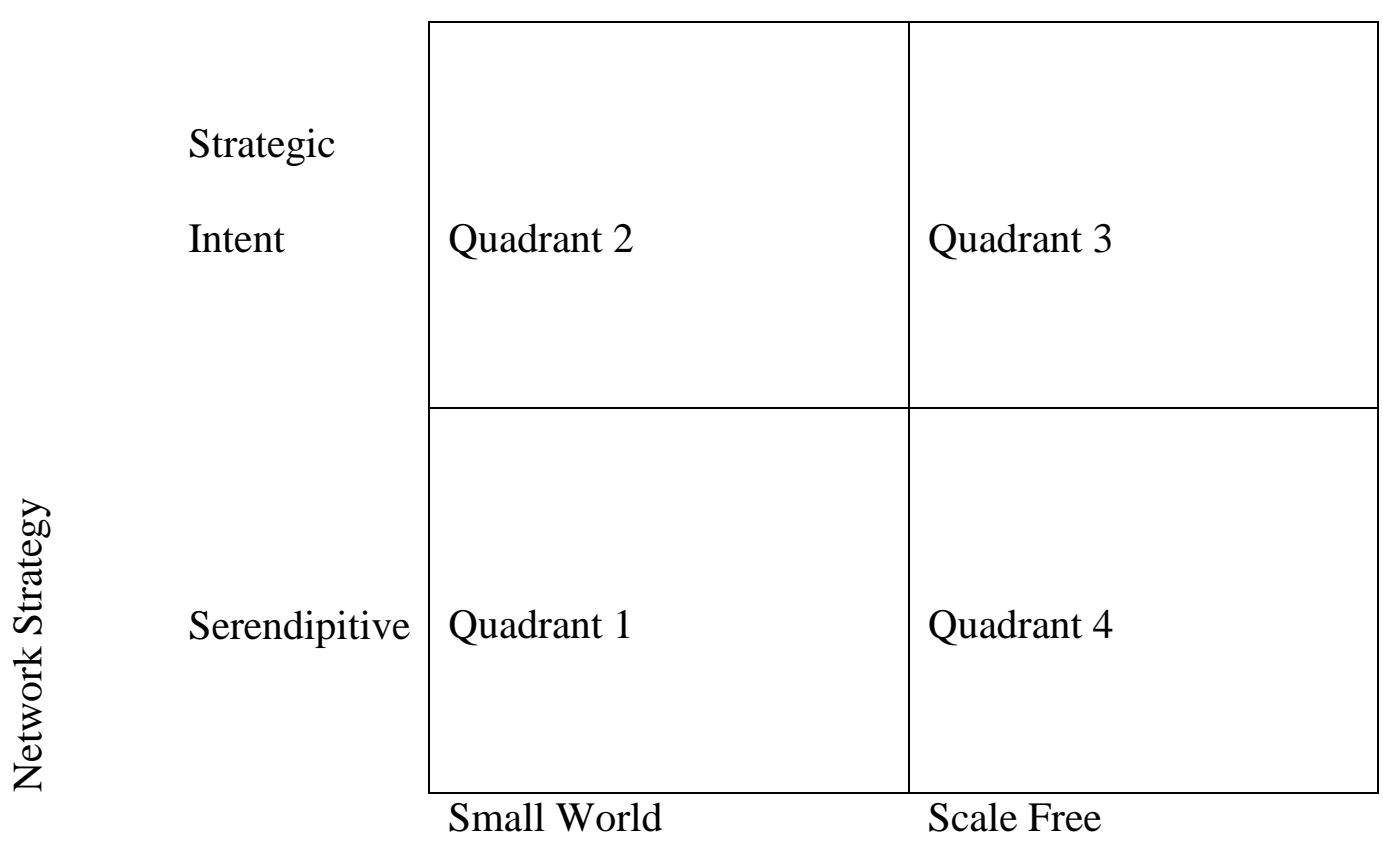

Network Structure 